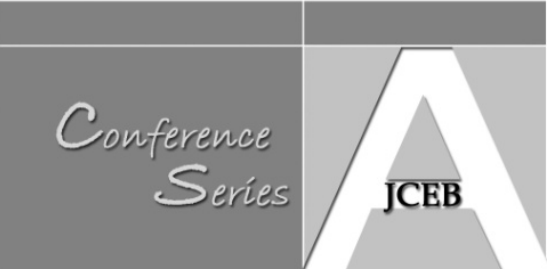

\title{
Construction Pathways: Attracting the Missing Students and Workers to University
}

Patricia McLaughlin (RMIT University, Melbourne, Australia) and Anthony Mills

(Deakin University, Geelong, Australia)

\begin{abstract}
The Commonwealth Government has the increased participation of under-represented groups to a $20 \%$ diversity target for Australian universities. It also has minimum targets of $40 \%$ of all Australians (25-34 years) holding a Bachelor's degree by 2020. These targets are baseline items in a government agenda of improving educational outcomes for Australians and pivotal in addressing skill shortages in industries such as construction. In construction there is a skewing of skill shortages to the higher order or post entry level skills. Demand for higher skilled occupations such as construction managers, outstrips demand for construction trades (DEEWR, 2010). But whilst $41 \%$ of the industry have VET qualifications, only $10 \%$ possess HE qualifications in construction. Movement between the VET and HE sectors is low: of all construction students qualifying at AQF 4, less than $10 \%$ continue on to higher education and less than $1 \%$ of VET qualified persons in the construction workforce seek reentry to university. This paper examines national data in construction education pathways and evaluates, using the DEMO matrix, the enablers in pathways to HE qualifications. The evaluation is based upon survey responses of two cohorts entering higher education from non-traditional pathwaysarticulating VET students and mature-aged workers. The results indicate that pathway programmes into construction degrees can attract non-traditional cohorts, but elements such as learner engagement, confidence, people-rich resources and collaboration are critical features of successful pathways.
\end{abstract}

Keywords: diversity, pathways, skills, tertiary education, construction,

\section{Introduction}

Australia, as a nation, is facing a national skill shortage. For the past decade robust economic growth has seen a tightening of the labour market with strong demand across many occupations. This demand has been spread unevenly with key industries such as engineering, and construction at the forefront of drastic skill shortages (DEEWR 2008; CPSISC 2010). More significantly, tertiary qualified professionals within these industries have been in continuing demand. Access Economics predicts that from 2010, demand for skilled professionals with bachelor qualifications across these industries will exceed supply levels. The shortfall in qualified workers is expected to then increase exponentially as the current labour force ages, the supply of available qualified people declines and industry requirements change (Access Economics 2008).

Tertiary institutions have a crucial role in developing the workforce of the future. Expanding student options and providing clear, fluid pathways to higher level qualifications in key industry areas is fundamental to meeting Australia's needs. To deliver the Australian Government target of an additional 217, 000 students at bachelor level or above by 2025, will require increased participation from groups not currently represented in higher education.

Increasing this participation in higher education will rely upon a number of factors. One key factor will be the increased access to higher education from individuals with VET qualifications. Pathways to lifelong learning must be part of the provision of mainstream 
tertiary education and not confined to special access, limited articulation or entry programmes. The interconnection between vocational and higher education must be enhanced. Skill needs and future work opportunities do not recognise the boundaries of VET and HE currently in place in all states of Australia. Australian industries require individuals with skills and knowledge from both VET and HE sectors.

At present student transition between VET (AQF levels 5, 6) and Higher Education (AQF level 7) is problematic and often haphazard with many students not accessing or not aspiring to higher education. This is a significant social, economic and cultural loss to both the individual and the nation. Bradley (2009, p. 181) notes that "much remains to be done to improve connectedness and ensure that pathways operate efficiently for all Australians".

Whilst distinct sectors are important (Bradley et al. 2008), there is a more pressing need to create better, universal and transparent pathways across tertiary education for building and construction students. Employers value higher-level skills and qualifications, mostly as a response to the context of globalisation, technological change, changes to the nature of work and skill shortages in the building and construction industries. However, the sector in which these qualifications are gained is of little relevance to employers. Employers argue for an integrated post-secondary skills environment where the difference between the sectors does not restrict the capacity of individuals to move between them. In many cases the mix of qualifications and skills required by the workplace spans both sectors (Foley 2007).

Most tertiary institutions have, at a policy level, embraced pathways and articulation models for students. Yet as Karmel (Cited in Walls and Pardy 2010) notes, the actual implementation is devolved to local alliances, partnerships or institutional arrangements that do not necessarily work in favour of the student. Current research still indicates substantial evidence of rigidities, inflexibilities and obstacles to learning and teaching that hinder individuals with VET qualifications accessing higher education with due recognition of their existing qualifications (NCVER 2010). The further development of seamless pathways between these AQF levels 5, 6 and 7 in particular, is a key objective of the Federal Government (AQFC 2009).

Raffe (2003) has suggested that seamless pathways between VET and HE are an attractive metaphor for policy makers and the reality is dissonances between the sectors of Australian tertiary education, divergence of policy intentions across state and national jurisdictions and multiple institutional practices that both enable and inhibit student mobility. Yet in spite of these disconnects, excellent pathways models exist. A number of researchers have highlighted successful models across disciplines (Harris et al. 2006; Walls and Pardy 2010; Wheelahan 2011) and in the building and construction discipline (McLaughlin and Mills 2009). The key aim of this research was to analyze successful pathways models that maximise student outcomes in the building and construction industry and to determine the enabling factors that operate for students within these models. The outcomes give insight into the enabling factors that create upskilling between VET and HE in the building and construction industry and provide informed avenues to increase the number of qualified individuals in the industry, thus improving the economic and social future of the nation

\section{The Australian Construction Industry}

The construction industry is extremely important to the Australian economy. The industry employs one in seven people in Australia and is the fourth largest employer with nearly one million employees. The industry contributes $\$ 61$ billion or $12 \%$ of GDP per annum (ABS 2010)

McLaughlin, P and Mills, A. (2012) 'Construction pathways: attracting the missing students and workers to university', Australasian Journal of Construction Economics and Building, Conference Series, 12 (1) 94-105 
Despite the economic and national significance of the industry, it has one of the least qualified workforces, (see Figure 1) with significant skill gaps at the higher levels of the AQF from Diploma level (AQF 5) upwards. Data from the ABS Survey of Education and Training (2009) provides an overview of the current qualifications profile of persons employed in the construction industry. Drawing on this data, the following observations are evident:

- Only a very small percentage of the construction workforce has AQF 7 (Bachelor degree) qualifications.

- The total tertiary qualified workforce in construction (Diploma/AQF 5 and above,) is only $12 \%$

- A massive $47 \%$ of the workforce has no post school qualifications.

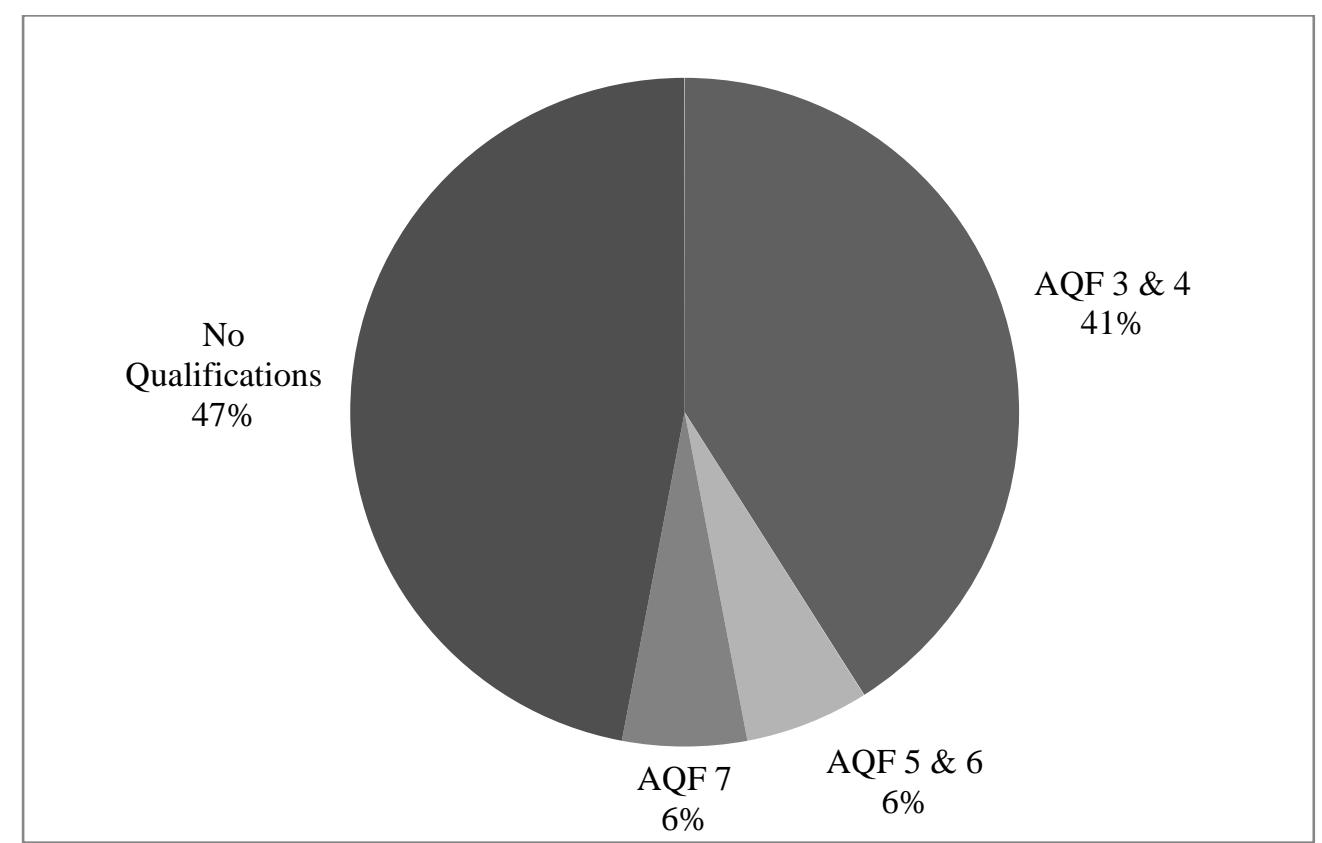

Figure 1: AQF Qualifications levels of Building and Construction industry workforce (Source: ABS Education and Training Experience, 2009)

With nearly half the workforce in the Australian construction industry having no formal credentialed post-school qualifications and only a very small number of people in the industry having higher level qualifications, the industry skill levels are stubbornly skewed to the lower levels of the Australian Qualifications Framework. Significantly the building and construction industry is also well above the national labour force industry average for those 25-44 year olds who lack any formal qualification (31\%) whatsoever (ABS 2008). This qualification profile at the higher AQF levels is significantly below other key industries of similar size by employment and contribution to the economy as set out in Table 1 . In comparative terms with other industries of similar GDP contribution, this makes the Australian Construction industry one of the least qualified industries with little evidence of upskilling or transition between VET qualifications and HE qualifications. Although there are State by State differences in enrolment figures, the number of Building and Construction Diploma and Advanced diploma students constituted only 6\% of all AQF enrolments in this Field in 2010. This figure is almost half that for AQF level 5 \& 6 qualifications generally in other industry fields which comprise $15.8 \%$ of all AQF qualifications students.

McLaughlin, P and Mills, A. (2012) 'Construction pathways: attracting the missing students and workers to university', Australasian Journal of Construction Economics and Building, Conference Series, 12 (1) 94-105 
Table 1: Industry comparisons of AQF 5, 6 \& 7 qualifications, Australia, 2009

Industry

\section{AQF Qualification}

Diploma/Advanced diploma Bachelor degree

Nos of persons \% of workforce No of persons \% of workforce

\begin{tabular}{lrrrr}
\hline Construction & 58,000 & 6.2 & 49000 & 5.9 \\
Manufacturing & 85600 & 8.8 & 99300 & 10.3 \\
Retail & 87100 & 8.3 & 103900 & 9.9 \\
Health services & 209700 & 18.1 & 285000 & 24.6
\end{tabular}

(Source: ABS Education and Training Experience, 2009, Item 6278, Table 11)

Alarmingly, of the small number of diploma students in building and construction Australia wide, an even smaller number continue to upskill beyond AQF level 5. The movement to HE is low, with only $1.6 \%$ of this AQF level 5 cohort continuing with on-going study at university. Table 2 sets out the rankings for on-going study at university.

Whilst this data only represents graduates of the 2010 year, and VET graduates from other years may go on to study at university at a later period of time, the key point is that in this industry the percentage of graduates moving on to further study is much lower than many other industries.

Table 2: VET Student Outcomes - Further Study at university, ranking by Industry Skills Council (ISC)

\begin{tabular}{|l|l|l|}
\hline Rank & Industry Skills Council & Percentage going on to university \\
\hline 1 & Not assigned & 9.6 \\
\hline 2 & Business Services & 9.1 \\
\hline 3 & $\begin{array}{l}\text { Services (Retail, Tourism \& } \\
\text { Hospitality) }\end{array}$ & 9.0 \\
\hline 4 & Community services \& health & 8.1 \\
\hline 5 & Government & 5.6 \\
\hline 6 & Agrifoods & 2.9 \\
\hline 7 & Manufacturing & 2.1 \\
\hline 8 & Transport & 2.0 \\
\hline 9 & Construction & 1.6 \\
\hline 10 & Electro/Electrical & 1.1 \\
\hline 11 & Skills DMC & $*$ \\
\hline 12 & Forestry & $*$ \\
\hline & ALL & $\mathbf{6 . 8}$ \\
\hline
\end{tabular}

(Source: NCVER Student Outcomes Survey, 2010. NCVER, 2011)

Karmel (2010) notes that the movement between VET (AFQ levels1-5) and HE (AQF 6-10) takes place on a spectrum ranging from well organised to haphazard. Student mobility between the sectors or AQF levels is not linear- in many cases policy and organisational processes lag behind the patterns of lifelong learning careers of students (McLaughlin and

McLaughlin, P and Mills, A. (2012) 'Construction pathways: attracting the missing students and workers to university', Australasian Journal of Construction Economics and Building, Conference Series, 12 (1) 94-105 
Mills 2010). Research by Harris et al. (2006) identified the issues as "crazy paving” which describes how student demand drives movement between the sectors in random and unexpected pathways. The phenomenon involves indirect transfer, where movement of tertiary students is not linear, but instead involves several moves within and between institutions and sectors.

Of all disciplines, the building and construction discipline has been one of the weakest in promoting movement between the VET and HE sectors. The industry skill levels and the tertiary institutions providing VET and HE qualifications to the industry are significantly divided. There is very little upskilling or transition of students between vocational education (up to AQF level 5) and higher education (beyond AQF level 6) in the building and construction disciplines.

Whilst research indicates evidence of some existing excellent pathways initiatives between VET and HE, (Moodie 2010) there is little evidence that the construction industry has benefitted from such upskilling pathways. Building and construction industry students and workers remain stubbornly under-represented in tertiary pathways.

There is a pressing need for the construction industry to invest in employees with higher-level skills and qualifications and to provide support for those with lower qualifications to move into diplomas/AQF 5 and beyond. The qualification hump in this industry, which essentially stalls at Certificate, III/IV needs to be extended.

Whilst higher education is not necessarily better for all individuals in terms of life choices or economic prosperity, there is considerable evidence that access to upskilling is vital for industry development and employability of individuals over time. Access to formal upskilling is important for a number of reasons (Construction and Property Services Industry Skills Council (CPSISC) 2010). These include:

- The physical demands of construction occupations, particularly trades. The impact of an ageing workforce coupled with physical requirements of the work means older workers need new skills to work in less physically demanding jobs in the industry.

- The changing skill requirements of the industry mean that initial entry level skills training at AQF 3 \& 4 can become outdated over an individual's lifetime in construction, particularly in areas such as technology, materials and energy usage and application.

- Regulatory and compliance issues are increasingly becoming more complex in the industry. Initial training is quickly outdated resulting in compliance concerns with existing workers.

- The organisation of work is changing. Pre-fabrication and PM techniques mean new work organisation which requires new skills for workers to remain employable.

- Environmental and OHS considerations are constantly reviewed, requiring re-skilling and upskilling for existing workers to remain safe and aware of changing work requirements and opportunities.

The industry workforce of Certificate III and below is at high risk during periods of economic downturn. For employees already in the industry, strategies are needed to upgrade qualifications, particularly amongst older workers who are at the greatest risk of redundancy or reduced physical capacity but who have the skills and experience to support entry into higher-level qualifications and higher level construction occupations.

McLaughlin, P and Mills, A. (2012) 'Construction pathways: attracting the missing students and workers to university', Australasian Journal of Construction Economics and Building, Conference Series, 12 (1) 94-105 
Persistent skill shortages and skill gaps in this industry reflect the inflexibility and lack of upskilling. Narrow entry-level training that encourages students to exit at the AQF level 3 or 4 , and a higher education focus on the professions has been to the long- term detriment of the students and the industry. In effect the industry is not capitalising on the total potential of its workforce with most qualified students exiting at AQF 4 or 5. Without a thorough investigation of the reasons for students not aspiring to further education and an examination of those pathways models that promote retention of building and construction students, the skills and knowledge base of the industry will continue to suffer. The flow-on effect to other industries is substantial.

In essence, the building and construction industry is perfectly placed to address increased participation and improved access from VET to HE. It has one of the most diverse labour forces in Australia, with very few building and construction students or workers seeking HE qualifications (AQF 6 and above). In the building and construction industry the divide between vocational qualifications (AQF levels 1-5) and higher education qualifications is stark. It is important to examine this divide and promote improved movement between these levels to fully utilise the skills of the individuals. Without this movement the industry cannot deliver a skilled future workforce for Australia.

\section{Aim of the Study}

The aim of this study was to determine the enabling factors that operate for students to create upskilling between VET and HE in the building and construction industry. The specific nexus between AQF 5 or AQF 6 and AQF 7 was integral to this objective.

The study attempted to examine examples of successful building and construction pathway "enablers"- that is, characteristics of pathways models where students who aspired to achieve qualifications beyond VET were successfully able to do so. This study examined two cohorts of students:

- A cohort of students who had commenced in a TAFE/VET course and had successfully upskilled to a construction degree $(n=90)$; and

- a cohort of industry-employed workers undertaking study, who were currently engaged in an upskilling programme $(n=22)$.

\section{Study Methods}

To ascertain examples of successful enablers, a national survey (questionnaire) of building and construction students in Australian tertiary institutions in 2011 was conducted. The research study and the national survey was funded by the Australian Learning and Teaching Council and encompassed five universities, all of which have large cohorts of construction students. . All of the survey respondents were enrolled in construction degrees (AQF level 7). The overall response rate was 33\% (179/542) indicating that the survey represented a sufficiently large sample of construction students of the total enrolled in these five universities. Of this cohort, 90 students had commenced at TAFE/VET and were now upskilling to AQF 7. These 90 students formed the first cohort of the study. The second cohort were enrolled in a TAFE Graduate Certificate in Construction and wished to upskill to an AQF 7 degree in construction. These students numbered 22 in total. The survey responses of the mature-aged workers were undertaken earlier in 2010.

McLaughlin, P and Mills, A. (2012) 'Construction pathways: attracting the missing students and workers to university', Australasian Journal of Construction Economics and Building, Conference Series, 12 (1) 94-105 
The responses both cohorts were examined against a Matrix developed by Gale et al. (2010) at the National Centre for Student Equity in Higher Education The matrix provides a conceptualization of the relationship between particular features of effective programs that are designed to improve equity and access of under-represented students in higher education.

Drawing on the international research literature and on these exemplars, Gale et al. (2010) found that programs that are quite likely to increase the number of under-represented students going on to higher education than otherwise would have been the case, exhibit a number of characteristics and strategies within these characteristics. These characteristics are (Gale et al. 2010, p.12):

- Assembling Resources -such as appropriate people, finances, early provision of resources

- Engagement of Learners- such as enhanced curricula, recognition of differences, research

- Working Together-such as collaboration and cohort-based focus and

- Building Confidence- such as communication, information and familiarisation

These characteristics, strategies and perspectives form the basis of a meta-analysis, named the Design and Evaluation Matrix for Outreach (DEMO). The DEMO Matrix foregrounds program conceptualisation and design as significant factors contributing to the likelihood of programs such as pathways making a difference for under-represented students.

The DEMO Matrix emphasises the importance and value of combining characteristics and draws attention to the strengthening of pathways programs that results from synergistic relationships between different characteristics and strategies. It is an ideal tool to categorise the diverse responses given for students undertaking higher education. The DEMO matrix has been specifically developed to evaluate the likelihood of success of particular programmes in under-represented and disadvantaged individuals accessing higher education. By applying it in this study, it can categorise the responses and predict the likelihood of the responses as "enablers of access" to higher education or upskilling in the construction discipline.

The respondents were questioned about the enabling factors in their movement from VET to Higher Education. In particular they were given the opportunity to respond in an open-ended manner to the questions;

- "What would you like say about your experience in moving from VET to Higher Education?” - for the cohort already enrolled in degrees (AQF7) and

- "Do you intend to complete further study in this area, why or why not?"- for the cohort not enrolled in degree (AQF7)

Analysis of these open-ended comments and answers to the above questions was undertaken using the DEMO matrix which effectively classifies features of the effective access programmes into four key areas of:

- Assembling resources

- Engaging learners

- Working together

- Building confidence.

McLaughlin, P and Mills, A. (2012) 'Construction pathways: attracting the missing students and workers to university', Australasian Journal of Construction Economics and Building, Conference Series, 12 (1) 94-105 
Gale et al. (2010) developed the DEMO Matrix based upon national and international literature and studies that identified characteristics, strategies and perspectives that are likely to increase the number of "under-represented" students going on to higher education than would otherwise have been the case. By applying the DEMO Matrix to the responses made by the TAFE/VET articulants and those mature-aged workers studying at VET levels, insights into elements of successful pathways can be gained.

By ascertaining the enabling factors for two cohorts who were engaged in upskilling pathways or wanted to engage in upskilling, the researchers were able to establish critical factors that contributed to student transitions and maximisation of the student outcomes. By aligning the questions to the DEMO Matrix characteristics, the questionnaire was also able to elicit responses about enabling strategies embedded within these characteristics. By surveying one student group- who had already upskilled and a second group aspiring to upskill, a comparison of the characteristics and enablers was possible.

The results of this questionnaire and the comparison between the two cohorts are discussed in the next section.

\section{Results and Discussion}

Each of the open-ended comments by both cohorts was analysed using the DEMO Matrix. Results are detailed in the table below, using the DEMO Strategy Indicators.

Table 3: Open-ended comments categorised by DEMO Strategy Indicators

\begin{tabular}{l|c|c}
\multicolumn{1}{c|}{ DEMO Strategy } & $\begin{array}{c}\text { Group One } \\
\text { TAFE/VET } \\
\text { Articulants }\end{array}$ & $\begin{array}{c}\text { Group Two } \\
\text { Industry Workers* }\end{array}$ \\
\hline Assembling Resources & $35(79 \%)$ & $15(50 \%)$ \\
\hline Engaging Learners & $2(4 \%)$ & $1(3 \%)$ \\
\hline Working Together & $1(2 \%)$ & $12(40 \%)$ \\
\hline Building Confidence & $6(14 \%)$ & $\mathbf{3 0 *}$ \\
\hline \hline \multicolumn{2}{c|}{ Total } & $\mathbf{4 4 *}$ \\
\hline
\end{tabular}

Note: * A number of respondents gave more than one strategy in response.

The DEMO Strategy of Assembling Resources is identified by a number of characteristics. In responding to open-ended questions about TAFE/VET experiences, 35 comments from the group one articulants and 15 comments from workers cohort related to the issues relevant to Assembling Resources. The most common characteristics of assembling resources are identified by Gale et al (2010) as people rich elements, financial support and early, long term sustained approaches to transition to higher education.

Both cohorts in this study - TAFE articulants and industry workers recorded high responses to this strategy of Assembling Resources. In particular both groups noted the

McLaughlin, P and Mills, A. (2012) 'Construction pathways: attracting the missing students and workers to university', Australasian Journal of Construction Economics and Building, Conference Series, 12 (1) 94-105 
people-rich characteristic of successful enablers. This is illustrated in comments and statements from the articulants such as:

"The TAFE teachers really encouraged me to go on to further study", and

"If it wasn’t for Mr. X, I would not be here today."

Whilst comments from industry workers included such people-rich enablers as

"It seems Mr. Y knows everything about getting further qualifications. I am lucky to have found him to help me."

In both cohorts the presence of individuals who knew about upskilling and potential pathways was an important dominant pathways enabler. Equally the establishment of relationships with these individuals that included mentoring, guidance and support was seen as paramount to both cohorts.

Similarly when commenting upon what Gale et al (2010) calls sustained intervention, both cohorts realised the value of information that was timely, correct and constantly reinforced. This is underlined by comment from the industry cohort:

"Vince is really great, he goes out and finds further study opportunities and then keeps reminding you of the deadlines for applications."

From this sample study the important enablers to upskilling in the construction industry appear to be people-rich relationships where mentoring, guidance and support are paramount, along with an understanding of the capacity of the student cohort.

In this study, very few $(n=2)$ of the TAFE articulants and even fewer $(n=1)$ of the workers cohort made comments about engagement. Gale et al. (2010) in characterising engagement of learners as an element of successful transition or upskilling identifies recognition of difference as a crucial requirement. Neither cohort in this study made comments about the valuing of individual difference as an important enabling factor nor did they make mention of the differences in pedagogy. Only one student in the articulants groups noted that "university assignments are harder" and only one student in the workers cohort was worried about "how hard university will be." In terms of upskilling there was no response about enhancement of the curriculum or preparation for future (higher level) study.

As noted earlier the open-ended comments were deliberately selected for this paper to allow personal "voices" of both cohorts to be heard. The results indicate that neither the articulants nor the working cohort was concerned about their ability to engage with the curriculum in higher education. Preparation for upskilling through curriculum pedagogy was not seen as an important enabler in this study.

It was in the characteristic of Building Confidence that the two cohorts differed in the identification of upskilling enablers. For those individuals who were in the workers cohort, almost 50\% $(n=12)$ identified Building Confidence as an enabler to higher education. This is contrasted with the articulants $(n=6)$ who saw characteristics of Building Confidence as important. Gale et al (2010) identify familiarisation as an important element of building confidence as well as communication and information. It may well be that the students in the articulant group did not comment as they were already in higher education programmes and had acquired "confidence" by making the transition.

It may be supposed that once in higher education, information about transition or how to get there is no longer relevant. The workers cohort - who were all interested in upskilling,

McLaughlin, P and Mills, A. (2012) 'Construction pathways: attracting the missing students and workers to university', Australasian Journal of Construction Economics and Building, Conference Series, 12 (1) 94-105 
indicated information and communication as much more important enablers of transition than the student articulant group. Their comments reflect this concern and interest:

"I think all students should be given information about getting into higher education whether they want it now or not."

"We should be told all the possible pathways and then we can make an informed decision."

As enablers, information provision, communication and familiarisation were all rated highly by the industry workers. Whilst the importance placed upon this enabler was less than the importance of assembling resources by the participants in this study, it was still noted by almost $50 \%$ of the respondents who were industry workers. There may be some evidence that building confidence is mostly relevant for those "outside" the higher qualification, not those already in the degree.

\section{Conclusions}

This study has identified a number of important "enablers" of upskilling in the building and construction industry. Using the open-ended responses to a national survey to identify those issues that were most personalised by respondents, the study was able to compare two distinct cohorts: those individuals who were currently undertaking AQF 7 studies in construction after articulating from AQF 5 (TAFE) and the second cohort of individuals at AQF 5 who were currently employed in the industry and indicated they wished to upskill to AQF 7 level.

The results indicate that the main "enablers" of upskilling are identified by the respondents in this study as possessing two key characteristics of the DEMO Matrix:

- Assembling of Resources

- Building Confidence

Within the characteristic of Assembling Resources there are a number of identified strategies

- People rich strategies where individuals can access staff, mentors, administrators or friends who can advise support and encourage participation in higher education. Examples include specific TAFE staff or articulation/credit transfer officers.

- Early long-term resources that can influence participation and facilitate pathways. Examples include access/open days, workshops, briefings and pre-enrolment activity.

Within the characteristic of Building Confidence, there are a number of strategies -

- Communication strategies where individuals feel they have access to the latest data and opportunities to undertake appropriate higher education study. Examples include electronic communication, websites and credit transfer matrices.

- Information Provision strategies where accurate, relevant information is freely available.

Examples include posters, flyers, advertising, well publicised entry requirements and articulation information.

- Familiarisation strategies where aspirants to higher education gain insights into geographic, cultural and educational environments operating in higher education.

McLaughlin, P and Mills, A. (2012) 'Construction pathways: attracting the missing students and workers to university', Australasian Journal of Construction Economics and Building, Conference Series, 12 (1) 94-105 
Examples include campus visits, assessment methods, staff/student ratios and curriculum.

By identifying such strategies and categorising them using the DEMO Matrix, the respondents in this study have provided insights into enablers of further study or upskilling for construction students and workers. Although this study only examined open-ended responses of a sample of current students and workers in construction, it raises questions about the need for greater emphasis on resources provided to create upskilling opportunities for the construction industry and the need to build confidence amongst existing workers and students about aspiring to further qualifications. The study indicates the value of long-term information, communication and familiarisation strategies to increase diversity in higher education cohorts in construction and to provide opportunities for upskilling that meet personal needs and aspirations as well as industry requirements. The study reinforces the need for informed "people-rich" strategies that are not left to chance in tertiary environments. Most importantly the study provides. A valuable starting point for further analysis and a signpost for solutions to a better qualified Australian building and construction industry.

\section{REFERENCES}

Access Economics (2008). Future Demand for Higher Education - report for Department of Education, Employment and Workplace Relations, retrieved from: November'.http://www.deewr.gov.au/HigherEducation/Review/Documents/AccessEcono mics.pdf.

Australian Qualifications Framework Council (ACQF) (2009). Strengthening the AQF: A proposal: An analysis of submissions, retrieved from: http://www.aqf.edu.au/PoliciesPublications/tabid/196/Default.aspx.

Australian Bureau of Statistics (2008). Education and Work Cat. no. 6227.0., retrieved from: http://www.ausstats.abs.gov.au/ausstats/subscriber.nsf/0/656CB57FE56C0491CA25750C 000EF65B/\$File/62270_may\%202008.pdf

Australian Bureau of Statistics, (2010). A Statistical Overview of the Construction Industry, Cat. no. 1350.0. retrieved from: http://www.abs.gov.au/AUSSTATS/abs@.nsf/Lookup/1350.0Feature+Article1Oct+2010

Bradley, D., Noonan, P., Nugent, H. and Scales, B. (2008). Review of Australian Higher Education, Final Report, Commonwealth of Australia, retrieved from: http://www.deewr.gov.au/HigherEducation/Review/Pages/default.aspx

Construction and Property Services Industry Skills Council (CPSISC) (2010). Workforce Development Strategy: A Policy Paper by the Construction \& Property Services Industry Skills Council, retrieved from: http://www.cpsisc.com.au/resources/WD/Workforce_Development_Strategy_FINAL_Pap er_220211.pdf

Department of Education, Employment and Workplace Relations (DEEWR) (2008). Higher Education Statistics Collections, from: http://www.dest.gov.au/sectors/higher_education/publications_resources/statistics/publicat ions_higher_education_statistics_collections.htm

McLaughlin, P and Mills, A. (2012) 'Construction pathways: attracting the missing students and workers to university', Australasian Journal of Construction Economics and Building, Conference Series, 12 (1) 94-105 
Foley, P. (2007). The socio-economic status of vocational education and training students in Australia, National Centre for Vocational Education Research, Canberra, retrieved from: http://nla.gov.au/nla.arc-74701

Gale, T., Hattam R., Comber, B., Tranter, D., Bills, D., Sellar, S. and Parker, S. (2010). Interventions early in school as a means to improve higher education outcomes for disadvantaged (particularly low SES students, National Centre for Student Equity in Higher Education, Uni. of South Australia, Adelaide, SA, retrieved from: http://www.deewr.gov.au/HigherEducation/Publications/Pages/InterventionsEarlyInSchoo $\underline{\text { l.aspx }}$

Harris, R., Rainey, L. and Sumner, R. (2006). Crazy Paving or stepping stones? Learning pathways within and between vocational education and training and higher education, National Centre for Vocational Education Research, retrieved from: http://www.ncver.edu.au/publications/1722.html

McLaughlin, P. and Mills, A. (2009). Dual Sector Education: TAFE and Higher Education Collaborate in Construction Management, RMIT University, Melbourne.

McLaughlin, P. and Mills, A (2010). 'Parallel TAFE and higher education studies in Construction Management; From collaboration to dual qualification.' Proc. in AUBEA 2010 Construction Managements 35th Annual Conference, 14-16 July 2010, The University of Melbourne, Melbourne, Australia, pp.1-15.

Moodie G. (2010). Mixed-sector tertiary education: implications for self-accrediting and other higher education institutions, NCVER, Adelaide.

National Centre for Vocational Education Research (NCVER) (2010). Student outcomes, 2010, retrieved from: http:/www.ncver.edu.au/publications/2315.html

Raffe, D. (2003). 'Pathways linking education and work: A review of concepts, research, and policy debates.’ Journal of Youth Studies, 6(1), 3-19.

Walls, S. and Pardy, J. (2010). Crediting vocational education and training for learner mobility, National Centre for Vocational Education Research', (NCVER), Adelaide.

Wheelahan L. (2011). 'From Old to New: The Australian Qualifications Framework.' Journal of Education and Work, 24(3-4), 323-342.

McLaughlin, P and Mills, A. (2012) 'Construction pathways: attracting the missing students and workers to university', Australasian Journal of Construction Economics and Building, Conference Series, 12 (1) 94-105 